\title{
Reformas para quê? As políticas educacionais nos anos de 1990, o "novo projeto de formação" e os resultados das avaliações nacionais
}

\author{
Mônica Ribeiro da Silva*
}

Cláudia Barcelos de Moura Abreu **

\section{Resumo:}

O Brasil vive um contexto de reforma educacional desde o início dos anos de 1990. O presente trabalho se propõe a situar a educação brasileira no âmbito das políticas públicas e faz, inicialmente, um breve histórico e contextualização da reforma educacional do período. Identifica seus primeiros enunciados relacionando-os às condições da educação vigentes no país no momento em que a reforma tem início. Discute o papel que tem ocupado as agências internacionais e as orientações de organismos multilaterais na formulação das políticas locais. Aponta, nesse âmbito, a criação de interlocutores que têm por finalidade promover a viabilização e cumprimento das metas estabelecidas nas parcerias, bem como dar respostas aos agentes parceiros. O trabalho demonstra que um dos principais alvos da reforma foi a mudança curricular, utilizada como estratégia para aproximar a educação escolar das demandas postas pelas transformações ocorridas na economia em geral e no mundo do trabalho em particular. Evidencia a consolidação de um novo projeto de formação com destaque para a formação de professores. Analisa, por fim, os resultados desse processo de reforma tomando por referência o desempenho dos alunos aferidos por meio dos sistemas de avaliação nacional.

Palavras-chave: Reforma do ensino-Brasil. Avaliação educacional-Brasil. Políticas públicas-Brasil.

*Doutora em Educação, História, Política e Ciências Sociais pela Pontifícia Universidade Católica de São Paulo. Professora da Universidade Federal do Paraná.

**Doutora em Educação, História, Política e Ciências Sociais pela Pontifícia Universidade Católica de São Paulo. Professora da Universidade Federal do Paraná. 


\section{A Educação no âmbito das políticas públicas: histórico da reforma}

O Brasil vive um contexto de reforma educacional. Os principais indicadores que sinalizam a intencionalidade e implementação de mudanças são a Lei de Diretrizes e Bases da Educação de 1996 (BRASIL, 1996); as ações do Ministério da Educação que tomam por objeto as mudanças curriculares e a organização geral da escola, tais como os Parâmetros Curriculares Nacionais e o Sistema de Avaliação da Educação Básica; as Diretrizes Curriculares Nacionais propostas pelo Conselho Nacional de Educação; as políticas de financiamento, tais como a criação do Fundo Nacional de Desenvolvimento do Ensino Fundamental e, mais recentemente, o Fundo Nacional de Desenvolvimento da Educação Básica, dentre outras.

A reforma educacional tem uma de suas raízes fincada na Conferência Mundial de Educação para Todos, realizada em Jomtien - Tailândia, em março de 1990, da qual resultou, no país, o Plano Decenal de Educação para Todos (1993-2003). Essa Conferência, convocada pela Organização das Nações Unidas para a Educação, a Ciência e a Cultura (UNESCO), pelo Fundo das Nações Unidas para a Infância (UNICEF), pelo Programa das Nações Unidas para o Desenvolvimento (PNUD) e pelo Banco Mundial, contou com a presença de 155 países e traçou os rumos que deveria tomar a educação nos países classificados como E-9 - os nove países com os piores indicadores educacionais do mundo, dentre os quais, ao lado do Brasil, figuravam Bangladesh, China, Egito, Índia, Indonésia, México, Nigéria e Paquistão.

Dentre os principais indicadores da educação no Brasil no início da década de 1990 destacam-se o elevado índice de analfabetos adultos, próximo a 18 milhões de brasileiros; as altas taxas de evasão e repetência, aproximadamente $60 \%$ dos ingressantes no Ensino Fundamental (Ensino de Primeiro Grau, à época) deixavam de estudar por volta do quinto ano de escolarização e $91 \%$ dos que concluíam os oito anos da escolaridade obrigatória reprovavam pelo menos uma vez ao longo de sua trajetória escolar. O Ensino Médio (então Ensino de Segundo Grau) atendia a menos de 25\% dos alunos da faixa etária própria desse nível de ensino (15 a 17 anos).

Dentre as prioridades traçadas na Declaração Mundial de Educação para Todos (Education for All - EFA), consolidada em Jomtien e que tem 
no Brasil um de seus signatários, estão a redução das taxas de analfabetismo e a universalização do ensino básico, ${ }^{1}$ desde então, o governo brasileiro empreende um conjunto de ações com vistas a cumprir as metas firmadas nessa Declaração.

\section{O papel das agências internacionais}

As orientações de organismos como o Banco Interamericano de Desenvolvimento (BID) e o Banco Internacional de Reconstrução e Desenvolvimento (BIRD) têm produzido uma homogeneização das reformas nos mais diferentes países "parceiros".

A agenda traçada pelo Banco Mundial, por exemplo, inclui, dentre outras diretrizes, a busca do uso mais racional dos recursos estipulando que um fator primordial para isso seria a autonomia das instituições educacionais; recomenda que se dê especial atenção aos resultados, enfatizando a necessidade de que se implementem sistemas de avaliação; reforça a idéia da busca da eficiência e maior articulação entre os setores públicos e privados tendo em vista ampliar a oferta da educação.

Além dessas orientações, o Banco Mundial prescreve que as prioridades educacionais devem recair sobre a educação básica, e assim o justifica:

A educação, especialmente a primária e a secundária (educação básica), ajuda a reduzir a pobreza aumentando a produtividade do trabalho dos pobres, reduzindo a fecundidade, melhorando a saúde, e dota as pessoas de atitudes de que necessitam para participar plenamente na economia e na sociedade. (BANCO MUNDIAL apud SHIROMA et al., 2000).

Há, no entender do Banco, uma estreita vinculação entre educação e desenvolvimento econômico e entre educação e combate à pobreza, considerada uma ameaça ao crescimento econômico.

Ao longo dos anos 90, o Banco Mundial incorporou em sua agenda as definições traçadas em Jomtien, na Conferência Mundial de Educação para Todos (SHIROMA et al., 2000). Produziu o documento intitulado 
Prioridades y estratégias para la educación, publicado em 1995. Nesse documento, reafirma antigas posições, mas traça uma adequação de suas estratégias aos imperativos das mudanças na economia, fruto do processo de globalização e de reestruturação social e produtiva. Dentre as estratégias estão as orientações para a implementação dos sistemas de avaliação que, no Brasil, estiveram atrelados ao processo de reforma curricular.

Outro organismo que influenciou decisivamente os rumos da reforma foi a Comissão Econômica para a América Latina e Caribe (CEPAL) que, desde o início dos anos de 1990, afirmava a necessidade premente de adequação da educação escolar ao processo de reestruturação produtiva. Nessa direção indicava que se investisse em educação tendo em vista reformar os sistemas de ensino e "adequá-los a ofertar os conhecimentos e habilidades específicas requeridas pelos sistemas produtivos". Essa orientação foi traçada no documento Educación y conocimiento: eje de la transformación productiva com equidad, de 1990. (CEPAL-UNESCO, 1990)

Em parceria com a Organização das Nações Unidas para a Educação, Ciência e Cultura (UNESCO), a CEPAL e a Oficina Regional de Educação para a América Latina e Caribe (OREALC) definem, em 1992, as estratégias que os países da América Latina e Caribe deveriam seguir no intuito de buscar o crescimento econômico com eqüidade. $\mathrm{O}$ pressuposto básico para se alcançar tal objetivo estava nas vinculações entre educação e conhecimento e tinha como objetivo produzir uma educação na qual se articulassem cidadania e competitividade pela introdução de critérios que se orientassem pela eqüidade e eficiência e por diretrizes como integração nacional e descentralização.

É clara nas determinações da CEPAL e do Banco Mundial a orientação de que a reforma educacional e curricular deveria ocorrer, precipuamente, com o fim de adaptar a formação escolar às supostas demandas do setor produtivo. Isso contribuiu para um movimento no qual a extensão das mudanças econômicas extrapolasse o campo da produção e se configurasse em reestruturação geral da sociedade.

As preocupações em torno das mudanças na educação e a afirmação de sua centralidade foram alvo também da UNESCO. Esse órgão foi responsável pela produção, entre os anos de 1993 e 1996, do Relatório Delors, resultado dos trabalhos da Comissão Internacional sobre Educação para o Século XXI. O Relatório traça um diagnóstico da situação da 
educação mundial, começando pelas mudanças no cenário econômico. Afirma que o fenômeno da globalização iniciou-se no campo econômico e culminou em "um movimento em que todas as economias do mundo se tornaram dependentes dos movimentos de um conjunto mais ou menos importante de capitais, transitando rapidamente de um lugar para outro." (DELORS, 2000, p. 37). Aos poucos, esse processo tornou-se extensivo a outras esferas, como a da ciência e tecnologia e trouxe conseqüências para outras, como a da educação. O Relatório reconhece que a globalização favorece os países ricos e que os mais pobres permanecem sob o risco de serem excluídos. Com base nesse diagnóstico, estabelece uma série de indicativos que deverão ser observados pelos governos, sobretudo os dos países pobres, para que enfrentem as tensões postas pela realidade da mundialização capitalista.

Dentre as suas indicações está a da ampliação da educação básica que deveria voltar-se para o pluralismo e para a tolerância que desencadeará uma barreira contra a violência. Assinala que para isso deverá sustentar-se em quatro pilares: aprender a conhecer, aprender a fazer, aprender a viver juntos (viver com os outros) e aprender a ser.

A finalidade de uma educação que se volta para o "aprender a fazer" vincula a educação diretamente às razões do mercado de trabalho. Assim, a educação básica deve ter como um de seus pilares o aprender a faz̧er que, mesmo sendo indissociável do aprender a conhecer, "está mais estreitamente ligado à questão da formação profissional: como ensinar o aluno a pôr em prática os seus conhecimentos e, também, como adaptar a educação ao trabalho futuro quando não se pode prever qual será a sua evolução." (DELORS, 2000, p. 93).

Com relação ao ensino médio, o Relatório evidencia uma concepção seletiva desse nível, além de reforçar que "hoje em dia, para haver desenvolvimento é preciso que uma proporção elevada da população possua estudos secundários.” (DELORS, 2000, p. 134). O caráter seletivo do ensino médio é identificado em afirmações como: "Enquanto a educação básica, seja qual for a sua duração, deve ter por objeto dar resposta às necessidades comuns ao conjunto da população o ensino secundário deveria ser o período em que os talentos mais variados se revelam e desenvolvem." (DELORS, 2000, p. 135).

Muitas das orientações prescritas pela UNESCO, assim como pelo 
Banco Mundial e pelo Banco Interamericano, foram incorporadas pela política educacional brasileira que, ao longo da década, ocupou-se da implementação da reforma educacional. As bases para essa reforma foram traçadas, como é possível constatar, com base em uma intensa interlocução entre os atores locais e as agências internacionais.

\section{O cenário local: a produção de interlocutores e viabilizadores}

No âmbito local, o Estado brasileiro, desde o início da década, esforçou-se para o cumprimento das metas estabelecidas nas parcerias, bem como em dar respostas visíveis aos agentes parceiros. O Programa Brasileiro de Qualidade e Produtividade (PBQP), definido ainda no Governo Collor, apontava a direção que a reforma do Estado e da economia deveriam tomar. Conjugadas a elas estariam as mudanças na educação, delineadas no PBQP como um subprograma que estabelecia a necessidade de formulação de uma política educacional que tivesse como eixo a "educação para a competitividade".

O documento em pauta incorpora muitas das orientações que vinham sendo debatidas desde o início dos anos de 1990 pela UNESCO e pelo Banco Mundial. Dentre as similaridades vale ressaltar o indicativo de aproximação entre o ensino médio e o setor produtivo, bem como a implementação do sistema de avaliação, se bem que este já se encontrava em processo de implantação.

\section{O estabelecimento de um novo projeto de formação}

Como desdobramento do postulado da centralidade da educação básica - como visto acima, capitaneada pelos organismos multilaterais - a formação do professor apresenta-se como fundamental para a recomposição da esfera educacional sob novas bases, pois atua como elemento que pode instituir, por meio da sua prática cotidiana, a formação humana requerida para desenvolver a capacidade competitiva do país, visando preparar trabalhadores e consumidores com base na diversidade das condições sociais (ABREU; LANDINI, 2005).

Em resposta a esta demanda verifica-se desde a década de 1990 a implementação de políticas voltadas à formação de professores para a educação básica, pois o argumento oficial "associava o fraco desempenho na 
aprendizagem dos alunos à formação insuficiente de seu quadro docente." (DIAS; LOPES, 2003, p. 1.159). Como ponto extremo deste precário quadro de formação, destacam-se os índices relativos aos professores das escolas primárias sem nenhuma formação pedagógica.

Com base neste diagnóstico é possível constatar que as proposições oficiais se voltaram fortemente para a defesa de um projeto de formação posto por novos referenciais e um processo de avaliação que, articulados, poderiam elevar a qualidade de seus quadros e por decorrência elevar os indicadores positivos do processo de ensino-aprendizagem. Nesse sentido, se tomamos como referência as Diretrizes Curriculares Nacionais para a Formação de Professores da Educação Básica - Resolução CNE/CP de 2002 (BRASIL, 2002) constatamos a convergência entre o que dispõe o documento e as assertivas propostas alhures, principalmente no que se referem à pedagogia das competências tomada como base da formação e do processo de avaliação.

Pesquisadores do campo da educação apresentaram as críticas necessárias à pedagogia das competências, assim como às formas de controle postas pelos processos de avaliação (SILVA, 2007; FREITAS, 2003; LOPES, 2003; MANFREDI, 1998; MACHADO, 2002; RAMOS, 2001). Estas se referem ainda ao fato de que a formação em nível superior dos professores, demandada por amplos setores dos profissionais da educação, não tenha como lócus principal a universidade, retirando do professor a possibilidade de uma formação de cunho científico-acadêmico.

As críticas apontam também para a tendência presente na formação de professores de que

\begin{abstract}
a pesquisa (ou investigação) que se desenvolve no âmbito do trabalho de professor não pode ser confundida com a pesquisa acadêmica ou científica. Refere-se fundamentalmente a uma atitude cotidiana de busca de compreensão dos processos de aprendizagem e desenvolvimento de seus alunos e à autonomia na interpretação da realidade e dos conhecimentos que constituem seus objetos de ensino. (FREITAS, 2002, p. 45).
\end{abstract}

Desse modo, é possível constatar a concepção de teoria e prática 
presente no ideário oficial: a reflexão deve ser tomada pela ótica da prática, do que nos atinge cotidianamente, ou seja, retirar a formação de professores da formação científica e acadêmica própria do campo da educação, localizando-a em um novo "campo" de conhecimento: o da "epistemologia da prática". Verifica-se, portanto, nas políticas de formação docente a sua redução aos aspectos técnicos da atuação docente pela focalização, nestes programas, da sala de aula e das metodologias de ensino.

O processo de estabelecimento de novas bases para a formação de professores não tem conseguido reverter o quadro de precarização do trabalho docente no sistema educacional brasileiro. As investigações neste campo têm reiteradamente apresentado dados que sugerem uma crescente precarização das condições de trabalho do professor, em todos os níveis de ensino, mas fundamentalmente na Educação Básica (FREITAS, 2003; ABREU; LANDINI, 2003; APPLE, 1995); têm apontado para o fato de que o trabalho dos professores está cada vez mais submetido a um processo de desintelectualização de suas atividades (DIAS; LOPES, 2003; GIROUX, 1988) e têm apresentado análises sobre a legislação pertinente à formação de professores que indicam uma tendência fortemente utilitarista, pautada pelo desenvolvimento de habilidades para "dar respostas adequadas e fazer intervenções produtivas" (BRASIL, 2000, p. 36). Isto demonstraria a convergência com o "movimento que prioriza a eficiência e a construção de um terreno consensual que toma por base a experiência imediata ou o conceito corrente de "prática reflexiva", (MORAES, 2001, p. 2) cujo ponto fundamental desta 'utopia praticista' é o saber-fazer. Faz-se ainda necessário atentar para os estudos na área da saúde coletiva que têm, cada vez mais, constatado doenças laborais ligadas ao trabalho do professor (REIS, 2006; SOUZA, 2003).

\section{A reforma curricular e as avaliações nacionais: o que indica o desempenho dos alunos}

O Parecer 15/98, Diretrizes Curriculares Nacionais para o Ensino Médio (BRASIL, 1998), prescreve que sejam empreendidos mecanismos de avaliação do sistema educacional tendo em vista "aferir se os pontos de chegada estão sendo comuns" e prescreve que se tome como referência para 
tal avaliação "as competências de caráter geral que se quer constituir em todos os alunos e um corpo básico de conteúdos, cujo ensino e aprendizagem, se bem sucedidos, propiciam a constituição de tais competências." (BRASIL, 1998, p. 34). Essas prescrições se configuram como um dos fundamentos legais da implantação de dois dos sistemas de avaliação da Educação Básica no Brasil: o Sistema Nacional de Avaliação da Educação Básica (SAEB) e o Exame Nacional do Ensino Médio (ENEM).

As finalidades desses exames seriam a de permitir aos sistemas de ensino, por meio dos resultados das avaliações, bem como dos indicadores de desempenho,

avaliar seus processos, verificar suas debilidades e qualidades e planejar a melhoria do processo educativo. Da mesma forma, deveriam permitir aos organismos responsáveis pela política educacional desenvolver mecanismos de compensação que superem gradativamente as desigualdades educacionais. (BRASIL, 1998, p. 11).

No presente texto buscar-se-á evidenciar que as finalidades anunciadas ultrapassam, porém, as capacidades oferecidas pela aplicação de provas anuais, de caráter voluntário, no caso do ENEM, ou bianual mediante amostragem, no caso do SAEB.

A implementação de mecanismos de avaliação do sistema educacional precedeu as demais ações da reforma curricular implementada no Brasil desde o início da década. As primeiras ações em torno das avaliações nacionais se firmaram ao mesmo tempo em que se iniciavam as discussões oficiais em torno da LDB.

O Sistema Nacional de Avaliação da Educação Básica (SAEB) foi objeto de um projeto piloto em 1988, passando por alterações ao longo dos anos de 1990. Bonamino (2002) realiza um estudo minucioso dessa política de avaliação e analisa os diferentes ciclos de sua estruturação que caracterizam concepções e estratégias diferenciadas de avaliação. A autora assinala, ainda que "em sua origem, que o SAEB se relaciona com demandas do Banco Mundial relativas à necessidade de desenvolvimento de um sistema de avaliação do impacto do Projeto Nordeste, segmento Educação, no âmbito do VI Acordo MEC/BIRD²" (BONAMINO, 2002, 
p. 93). A implantação de sistemas de avaliação da educação em âmbito nacional é destaque também da Declaração Mundial de Educação para Todos, antes referida.

Dentre as primeiras razões que levaram o governo brasileiro a produzir os Parâmetros Curriculares Nacionais está a questão da exeqüibilidade de um sistema de avaliação nacional, como o SAEB e o ENEM. É possível constatar esta relação em afirmações como a da Secretária de Ensino Fundamental do MEC, quando, em entrevista à revista Nova Escola, no ano de 1995, afirma: "a existência de parâmetros curriculares facilita a avaliação do ensino, a formação de professores em âmbito nacional e a produção de livros didáticos. (PRADO apud MOREIRA, 1995, p. 102). Enfatiza ainda, na mesma revista, que "um dos grandes problemas que o Sistema Nacional de Avaliação da Educação Básica, organismo do MEC, tem enfrentado é justamente a inexistência de um parâmetro curricular nacional." (PRADO apud MOREIRA, 1995, p. 102).

Os ciclos de 1990 a 1995 do SAEB ainda não incorporavam a noção de competências como fundamento e metodologia de avaliação. A partir de 1997, tanto o SAEB (quarto ciclo), como o Exame Nacional do Ensino Médio (ENEM), com primeira aplicação em 1998, programam uma forma de avaliação estruturada com base na noção de competências. Bonamino (2002) constata que as mudanças das orientações e de formulação dos instrumentos de avaliação no quarto ciclo do SAEB visavam, dentre outras coisas, instituir um processo de aferição dos níveis cognitivos dos alunos. Para tanto, a prova deveria consistir de descritores de desempenho dos alunos obtidos pelo "cruzamento ou associação entre conteúdos curriculares e operações mentais (competências e habilidades)." (BRASIL, SAEB, apud BONAMINO, 2002, p. 153).

A noção de competências passou a ser incorporada nas matrizes curriculares de referencia (MCR) do SAEB por meio dos agentes formuladores que vinham de experiências anteriores com o construtivismo piagetiano. É o que retrata Bonamino (2002) no depoimento de coordenadores das MCR do SAEB:

Quando nós começamos o SAEB, não pensávamos ainda em termos de competências. Começamos de uma forma muito geral, e a partir das discussões, dos encontros do grupo com a Maria Inês [Fini] 
foram surgindo idéias e nós tivemos a idéia de trazer o texto original [preparado durante a experiência na Escola de Cadetes], que era muito simplesinho, pequenininho, sobre competências. O grupo leu, assimilou, discutiu, modificou a forma de ver, de sentir, e aí decidiu que nós utilizaríamos esse termo - "competências cognitivas" - e que, em cima disso, seriam feitos os descritores, para não ficar uma ênfase muito grande nos conteúdos. (BRASIL, SAEB, apud BONAMINO, 2002, p. 161).

O emprego da noção de competências não foi decorrente da opção por referências teóricas pré-definidas, mas resultou de posições acatadas coletivamente, advindas de referências difusas ao cognitivismo e ao construtivismo. É o que mostra o seguinte depoimento:

Nós fomos fazendo os descritores pensando nas competências que são necessárias para aprender e, a partir de determinado momento, alguém teve a idéia de determinar níveis diferentes: "vamos tentar colocar essas competências em três níveis?” Aí, a idéia que surgiu foi o nível básico, que seria o saberfazer. Depois, buscando na teoria, não foi antes, foi depois, buscando uma teoria, uma explicação, alguma coisa que desse suporte encontramos o Fazer e Compreender de Piaget. Então, o nível do fazer e dos procedimentos seria esse primeiro nível das competências básicas. Depois, o nível operacional, que não estava muito caracterizado como nível operatório, depois de discussões, depois de voltar, discutir, ele ficou bem próximo do segundo nível que seria o das operações. E o nível global que estaria relacionado à generalização, a abstrações maiores e à aplicação em outros contextos. Então você vê, não saiu da teoria diretamente. Nós fomos fazendo e buscando suporte na teoria. E em alguns grupos, nem em todos os grupos, tinha piagetianos. No nosso grupo tinha e estava bem mesclado. [...]

Então, nós fomos juntando [...] São teorias que não são incoerentes, senão não daria para fazer alguma 
coisa. Mas também não nos prendemos em uma só teoria, porque eu acho que para este tipo de trabalho você não pode ser purista, você tem que buscar. (BRASIL, SAEB, apud BONAMINO, 2002, p. 162).

Do exposto, evidencia-se que a noção de competências foi se firmando no interior do SAEB por meio de um movimento que mesclou a busca de respostas práticas sobre como formular instrumentos de avaliação à busca de teorias que fundamentassem as opções feitas. Dada a origem dos propositores, a perspectiva da Psicologia - especialmente de matriz piagetiana - firmou-se como principal fonte do uso da noção de competências. Esse processo se deparou, ainda, com a emergência do modelo de competências que se firmava na área da educação profissional.

Esse caminho possivelmente explica o fato de que as tentativas de se definir os termos competências e babilidades nos PCNEM e nos sistemas de avaliação resultaram em conceituações diversas. Nos Parâmetros Curriculares Nacionais, a explicitação do entendimento sobre esses termos mostra-se mais próxima das discussões que se vêm realizando no campo da Sociologia do Trabalho e das asserções em torno da necessidade de adequação da escola às demandas do mundo do trabalho. As referências ao cognitivismo piagetiano se fizeram de maneira menos direta nos PCNEM e nas DCNEN, porém, é a referência mais importante para o SAEB e para o ENEM.

Os encaminhamentos dados ao SAEB a partir de 1997 marcaram também os rumos dados ao Exame Nacional do Ensino Médio (ENEM) a partir de 1998. Com a finalidade de viabilizar um tipo de avaliação que conduzisse ao controle para averiguar a "eficácia" e a "eficiência" do(s) sistema(s) de ensino, a idéia de habilidades e competências está explicitada no Documento Básico do Exame Nacional do Ensino Médio por meio de uma "matriz de competências" com a finalidade de identificar as habilidades e competências que os alunos egressos do Ensino Médio deveriam dominar. Com base nelas, são definidos os critérios de avaliação bem como a elaboração das questões.

O Documento Básico do ENEM afirma que a Matriz de Competências foi construída "por um grupo de profissionais da educação - especialistas em Psicologia do Desenvolvimento, pesquisadores e professores das diferentes áreas de conhecimento e especialistas em psicometria." (BRASIL. 
MINISTÉRIO DA EDUCAÇÃO. INSTITUTO NACIONAL DE ESTUDOS E PESQUISAS EDUCACIONAIS ANÍSIO TEIXEIRA. Documento básico do ENEM: 1998, 2002). Pela explicitação do que esse grupo tomou como concepção de conhecimento evidencia-se que, desde o início, o ENEM estruturou-se com base na perspectiva piagetiana de competências:

\begin{abstract}
A concepção de conhecimento subjacente a essa matriz pressupõe colaboração, complementaridade e integração entre os conteúdos das diversas áreas do conhecimento presentes nas propostas curriculares das escolas brasileiras de ensino fundamental e médio e considera que conhecer é construir e reconstruir significados continuamente, mediante o estabelecimento de relações de múltipla natureza, individuais e sociais. (BRASIL. MINISTÉRIO DA EDUCAÇÃO. INSTITUTO NACIONAL DE ESTUDOS E PESQUISAS EDUCACIONAIS ANÍSIO TEIXEIRA. Documento básico do ENEM: 1998, 2002, p. 8).
\end{abstract}

Há quase 10 anos de sua criação, o ENEM mantém sua concepção original: "A estrutura conceitual de avaliação do Enem, delineada no Documento Básico, de 1998, que definiu as suas características gerais, vem sendo aprimorada e consolidada a cada aplicação do exame, sem, contudo, afastar-se dos fundamentos estabelecidos na concepção original." (BRASIL. MINISTÉRIO DA EDUCAÇÃO. INSTITUTO NACIONAL DE ESTUDOSE PESQUISAS EDUCACIONAIS ANÍSIO TEIXEIRA. ENEM: concepções..., 2007, p. 2). Dentre os aspectos reiterados nas sucessivas aplicações do Exame, permanece sua finalidade primeira, qual seja "avaliar o desempenho do aluno ao final da escolaridade básica, para aferir o desenvolvimento das competências e habilidades requeridas para o exercício pleno da cidadania." (BRASIL, MINISTÉRIO DA EDUCAÇÃO. INSTITUTO NACIONAL DE ESTUDOS E PESQUISAS EDUCACIONAIS ANÍSIO TEIXEIRA. ENEM: concepções... 2007, p. 2).

Nos Relatórios Pedagógicos do ENEM é reafirmada a idéia de que um dos eixos estruturais desse exame é a ênfase na resolução de problemas como forma de aferir competências e habilidades. Outro eixo é a ênfase na "avaliação das estruturas de inteligência". A inteligência é concebida como 
"uma estrutura de possibilidades crescentes de construção de estratégias básicas de ações e operações mentais com as quais se constroem os conhecimentos." (BRASIL. MINISTÉRIO DA EDUCAÇÃO. INSTITUTO NACIONAL DE ESTUDOS E PESQUISAS EDUCACIONAIS ANÍSIO TEIXEIRA. ENEM: relatórios pedagógicos... 2003, 2007, p. 31).

Com base nessa compreensão de inteligência, justifica-se que a avaliação tenha como foco a "aferição de competências e habilidades, com as quais transformamos informações, produzimos novos conhecimentos, reorganizando-os em arranjos cognitivamente inéditos que permitem enfrentar e resolver problemas." (BRASIL. MINISTÉRIO DA EDUCAÇÃO. INSTITUTO NACIONAL DE ESTUDOS E PESQUISAS EDUCACIONAIS ANÍSIO TEIXEIRA. ENEM: relatórios pedagógicos... 2003, 2007, p. 31). Esse Relatório enfatiza que o Exame está considerando o "estágio de desenvolvimento cognitivo" correspondente ao término da escolaridade básica, que, em conformidade com a "teoria do desenvolvimento cognitivo de Piaget", situa-se no período das operações formais, com o "advento do raciocínio hipotético-dedutivo".

Observa-se ainda, tanto nas proposições dos PCNEM e das DCNEM, quanto nos encaminhamentos do SAEB e do ENEM, que os formuladores do discurso oficial partiram da pressuposição de que o emprego da noção de competência fosse algo consensual, amplamente partilhada e de conhecimento, inclusive, por parte dos que teriam que lidar com essa referência sem terem, no entanto, se envolvido com o processo de definição dessas políticas, os professores. Essa pressuposição explica, por exemplo, a fluidez e as ambigüidades presentes na maneira com que é exposta a noção de competências nas poucas vezes em que se tenta defini-la ou nas inúmeras vezes em que é prescrita como resultado desejado da formação.

Nos Parâmetros Curriculares Nacionais para o Ensino Médio a palavra competências está definida como

[...] capacidade de abstração, do desenvolvimento do pensamento sistêmico, ao contrário da compreensão parcial e fragmentada dos fenômenos, da criatividade, da curiosidade, da capacidade de pensar múltiplas alternativas para a solução de um problema, ou seja, do desenvolvimento do pensamento divergente, da capacidade para trabalhar em equipe, da disposição 
para procurar e aceitar críticas, da disposição para o risco, do desenvolvimento do pensamento crítico, do saber comunicar-se, da capacidade de buscar conhecimento. (BRASIL. MINISTÉRIO DA EDUCAÇÃO. SECRETARIA DE EDUCAÇÃO MÉDIA E TECNOLÓGICA. Parâmetros..., 1999, p. 11).

No documento básico do ENEM verifica-se um distanciamento com relação à definição anterior:

Competências são as modalidades estruturais da inteligência, ou melhor, ações e operações que utilizamos para estabelecer relações com e entre objetos, situações, fenômenos e pessoas que desejamos conhecer. As habilidades decorrem das competências adquiridas e referem-se ao plano imediato do 'saberfazer'. Através das ações e operações, as habilidades aperfeiçoam-se e articulam-se, possibilitando nova reorganização das competências. (BRASIL. MINISTÉRIO DA EDUCAÇÃO. ENEM: documento básico, 2000; Documento básico: 1998, 2002, p. 5).

As ambiguidades próprias da noção de competências e a fluidez que adquire no interior dos textos normativos da reforma curricular e dos modelos de avaliação possibilitam a articulação dessas políticas ao discurso veiculado no âmbito dos textos oficiais, qual seja, o de que a escola deve mudar tendo em vista atender às demandas postas pelas mudanças ocorridas no mundo do trabalho devidas às inovações tecnológicas e organizacionais. Esse movimento conduz a uma subordinação da escola à lógica posta pela sociedade de mercado e deriva, ainda, da forma anistórica com que se procede à definição dos pressupostos e das prescrições curriculares e avaliativas.

\section{Avaliações de Estado e suas intencionalidades: a produção de adesão e controle sobre as escolas e seus atores}

A avaliação por meio de indicadores de desempenho mostra-se eficaz quando se trata de se exercer algum tipo de controle sobre a atividade escolar. Em um contexto de reforma educacional, na qual se pretende 
atingir o fazer pedagógico no interior da escola e nele provocar mudanças, a avaliação adquire ainda mais a conotação de estratégia de controle. Dentre as estratégias de adesão dos educadores com relação às proposições da reforma curricular firmaram-se os mecanismos de avaliação de Estado, como o ENEM e o SAEB. A esse respeito, afirma Lopes:

Tais indicadores de desempenho permitem a articulação dos sistemas de avaliação capazes de atuar no controle dos conteúdos ensinados. Assim, ainda que as propostas curriculares afirmem ser importante que as escolas assumam currículos flexíveis, adequados às suas realidades, capazes de permitir a cada escola a constituição de sua própria identidade pedagógica, os processos de avaliação centralizados nos resultados cerceiam tal flexibilidade. No caso do ensino médio, o Exame Nacional do Ensino Médio (ENEM) vem atuando significativamente sobre as escolas oferecendo padrões de condutas a serem cumpridos com base no modelo de competências. (LOPES, 2001, p. 8).

Os limites dos sistemas de avaliação nacional estão, no entanto, dados desde o seu pressuposto inicial e na metodologia que decorre desse pressuposto: o de que é possível conhecer a "produtividade" da escola por meio de um exame realizado nos alunos ao final de um período escolar. Desde há muito tempo as discussões em torno da avaliação do processo de ensino e aprendizagem têm afirmado que a ênfase da avaliação deve recair sobre os processos e não apenas sobre o "produto final", sobre os resultados.

É discutível também o caráter meritocrático atribuído aos sistemas de avaliação. Vincular a "produtividade" da escola à designação de recursos é agir dentro de uma lógica distributiva perversa que condena os que não obtiveram desempenho satisfatório a permanecerem nessa mesma condição. A atribuição de mérito, por meio dos mecanismos de premiação e punição, atua também como forma de pressão sobre as escolas para que passem a se orientar pelas determinações da reforma.

A concepção de avaliação classificatória e quantitativista, com base na mensuração de conhecimentos, se estende agora à avaliação de desempenho, 
tanto no caso do SAEB quanto do ENEM. No que se refere a este último, afirma-se:

Do ponto de vista cognitivo, a prova resulta da medida cuidadosa dos conhecimentos básicos, em termos de extensão e profundidade, considerados mínimos e significativos para o exercício pleno da cidadania, para o mundo do trabalho e para o prosseguimento de estudos em qualquer nível, a partir do término da escolaridade básica. (BRASIL. MINISTÉRIO DA EDUCAÇÃO. INSTITUTO NACIONAL DE ESTUDOS E PESQUISAS EDUCACIONAIS ANÍSIO TEIXEIRA, RELATÓRIO PEDAGÓGICO 2002, 2007, p. 43, grifo nosso).

Se os resultados das avaliações nacionais são representativos dos efeitos do processo de reforma curricular, vale a pena conhecer algumas de suas constatações. Para exemplificar, os resultados do SAEB 2001 mostraram que na maioria dos estados brasileiros os alunos da $4^{a}$ série do Ensino Fundamental ficaram na escala 2 de desempenho (de uma escala entre 1 e 8), excetuando o Distrito Federal e os estados do Rio Grande do Sul, Rio de Janeiro e São Paulo. De acordo com os indicadores desse exame, esses alunos "são capazes de ler sem dificuldade uma história infantil ou um comunicado aos pais. Mas nunca um texto mais complexo." (BRASIL. MINISTÉRIO DA EDUCAÇÃO. INSTITUTO NACIONAL DE ESTUDOS E PESQUISAS EDUCACIONAIS ANÍSIO TEIXEIRA. SAEB: 2005. PRIMEIROS RESULTADOS DO SAEB, 2005). Quanto aos alunos do $3^{\circ}$ ano do Ensino Médio, os resultados, para o país, mostraram que, em Língua Portuguesa, 4,92\% dos alunos encontravam-se em situação muito crítica; $37,20 \%$ em situação crítica e 52,24\%, em situação intermediária. Apenas 5,32\% tiveram um desempenho considerado adequado de acordo com os requisitos da prova. Em Matemática, esses indicadores estiveram assim distribuídos: 4,84\% em situação muito crítica; $62,60 \%$ em situação crítica; $26,58 \%$ em situação intermediária e, 5,99\% foram considerados com desempenho adequado. Fica evidenciado, também, que não houve alteração significativa dos resultados para os alunos da $8^{a}$ série do Ensino Fundamental e da $3^{\text {a }}$ série do Ensino Médio entre o exame de 1999 e o de 2001. Para os alunos da $4^{a}$ série do Fundamental verificou-se uma "variação 
negativa de 5 pontos em Matemática e de 6 em Língua Portuguesa", ou seja, o desempenho desses alunos decresceu. (BRASIL. MINISTÉRIO DA EDUCAÇÃO. INSTITUTO NACIONAL DE ESTUDOS E PESQUISAS EDUCACIONAIS ANÍSIO TEIXEIRA. SAEB: RELATÓRIOS... 1999 e 2001, 2005). A série histórica do SAEB entre os anos de 1995 e 2005 evidencia que o desempenho dos alunos, em todas as etapas avaliadas, foi decrescente.

Tabela 1 - Médias de proficiência em Língua Portuguesa-Brasil: 1995 2005

\begin{tabular}{c|c|c|c|c|c|c}
$4^{\text {a }}$ série do E. F. & 188,3 & 186,5 & 170,7 & 165,1 & 169,4 & 172,3 \\
\hline $8^{\text {a }}$ série do E. F. & 256,1 & 250,0 & 232,9 & 235,2 & 232,0 & 231,9 \\
\hline $3^{\text {a }}$ série do E. F. & 290,0 & 283,9 & 266,6 & 262,3 & 266,7 & 257,6 \\
\hline
\end{tabular}

Fonte: BRASIL. Ministério da Educação. Instituto Nacional de Estudos e Pesquisas Educacionais Anísio Teixeira. SAEB 2005 (2007). Primeiros resultados: médias de desempenho do SAEB/2005 em perspectiva comparada. Fevereiro 2007.

Tabela 2 - Médias de proficiência em Matemática-Brasil: 1995 - 2005

\begin{tabular}{|l|l|l|l|l|l|l}
\hline $4^{\text {a }}$ série do E. F. & 190,6 & 190,8 & 181,0 & 176,3 & 177,1 & 182,4 \\
\hline $8^{\text {a }}$ série do E. F. & 253,2 & 250,0 & 246,4 & 243,4 & 245,0 & 239,5 \\
\hline $3^{\text {a }}$ série do E. M. & 281,9 & 288,7 & 280,3 & 276,7 & 278,7 & 271,3 \\
\hline
\end{tabular}

Fonte: BRASIL. Ministério da Educação. Instituto Nacional de Estudos e Pesquisas Educacionais Anísio Teixeira. SAEB 2005 (2007). Primeiros resultados: médias de desempenho do SAEB/2005 em perspectiva comparada. Fevereiro 2007.

No que diz respeito ao ENEM, este obteve adesão crescente. A taxa de abrangência saltou de 12,40\% em 2000 para 47\% em 2001. Em 2002, $76 \%$ dos concluintes do Ensino Médio no país fizeram esse exame. Houve uma expansão significativa da participação de estudantes da escola pública. Segundo o Relatório Pedagógico do ENEM 2003:

Quanto ao perfil dos participantes do ENEM 2003, não houve em média, grandes diferenças do perfil 2002. A população participante do ENEM continua sendo a maioria do sexo feminino $(60 \%)$; cerca de 
$58 \%$ estão na faixa etária de até 18 anos de idade (inclusive); mais de 50\% declararam ser de cor branca; $34 \%$ de pardos ou mulatos; $7 \%$ de negros; $5 \%$ de amarelos e menos de $1 \%$ de indígenas. (BRASIL. MINISTÉRIO DA EDUCAÇÃO. INSTITUTO NACIONAL DE ESTUDOS E PESQUISAS EDUCACIONAIS ANÍSIO TEIXEIRA. ENEM: relatórios..., 2003, 2007, p. 8).

Os resultados do ENEM mostraram que desses alunos, os oriundos das redes públicas somaram $84,5 \%$ e situaram-se na faixa de desempenho entre zero e 40 na prova objetiva, ${ }^{3}$ isto é, entre insuficiente e regular pelos critérios do exame. Na comparação dos dados do ENEM 2001 e 2002 observa-se que houve um decréscimo no desempenho dos alunos de escola pública: aumentou de $67,6 \%$ para $84,5 \%$ o percentual dos que tiveram desempenho "insuficiente a regular". (BRASIL. MINISTÉRIO DA EDUCAÇÃO. INSTITUTO NACIONALDE ESTUDOS E PESQUISAS EDUCACIONAIS ANÍSIO TEIXEIRA. ENEM: relatórios..., 2007).

A média geral da "parte objetiva" do ENEM, em 2002, foi de 34,13, o que situa o desempenho médio - entre alunos provenientes das redes públicas e das escolas privadas - na faixa de "insuficiente a regular". De todos os participantes, $74 \%$ ficaram nessa faixa, $23 \%$ na faixa de regular e bom e apenas $2,5 \%$ na faixa de bom a excelente. Ainda segundo este relatório, "para todos os segmentos internos às variáveis selecionadas, embora as médias não alcancem valores altos, a escola particular apresenta-se, invariavelmente, melhor do que a escola pública." (BRASIL. MINISTÉRIO DA EDUCAÇÃO. INSTITUTO NACIONAL DE ESTUDOS E PESQUISAS EDUCACIONAIS ANÍSIO TEIXEIRA. ENEM: relatórios... 2002, 2007, p. 176).

O Relatório Pedagógico do ENEM 2003 mostra que 35,7\% dos alunos tiveram um desempenho que os insere na faixa de desempenho descrita como "insuficiente a regular" na "parte objetiva" da prova; 49,5\% situaram-se na faixa "regular a bom" e 14,9 na faixa "bom a excelente", incluindo-se alunos das redes pública e particular. No relatório do ENEM $2003,{ }^{4}$ os dados disponibilizados até o momento não permitem dimensionar o desempenho exclusivo de alunos da rede pública. 
Os resultados comparativos do ENEM e do SAEB entre os anos de 1995 e 2005 corroboram a hipótese de que os procedimentos da reforma curricular por meio dos Parâmetros Curriculares Nacionais e das Diretrizes Curriculares Nacionais pouco influíram no desempenho qualitativo dos alunos, fragilizando a intencionalidade manifesta no âmbito dos exames nacionais de se efetivarem como instrumentos de gestão educacional tendo em vista produzir alterações qualitativas no desempenho da escola pública.

\section{Considerações finais}

Passou-se mais de quinze anos desde que teve início a atual reforma educacional. Firmaram-se convênios e parcerias com as agências internacionais; criaram-se vários interlocutores em âmbito nacional com vistas a alterar o quadro educacional do país. Mas, o que revelam os dados sobre a educação brasileira na atualidade?

Segundo dados do Instituto Nacional de Estudos e Pesquisas Educacionais Anísio Teixeira/Ministério da Educação (INEP/MEC), no ano de 2003 o Brasil possuía cerca de 16 milhões de analfabetos com 15 anos ou mais e próximo a 30 milhões de analfabetos funcionais, conceito utilizado para definir pessoas com menos de quatro anos de estudos. A população analfabeta totaliza $13 \%$ da população. Essa taxa é de $8 \%$ no México e zero $\%$ no Canadá. Quase a metade dos 30 milhões de trabalhadores brasileiros com carteira assinada não passou do Ensino Fundamental, ou seja, possui menos de oito anos de escolaridade.

Os dados são igualmente preocupantes quando observada a taxa média de escolaridade, próxima dos cinco anos, contra 12 nos Estados Unidos e sete no México. O país conta, ainda, com alto índice de repetência, cerca de $21 \%$ dos alunos reprovam ao longo dos oito anos do Ensino Fundamental a cada ano. Dados do INEP de 2004 evidenciam que $75 \%$ das crianças na quinta série do Ensino Fundamental não sabem ler e escrever ou o fazem de forma precária.

No que diz respeito à formação docente, em 2001, próximo a 18\% dos professores que atuam no Ensino Fundamental são leigos, isto é, não possuem formação específica para atuar no magistério. Destes, por volta de $6 \%$ têm menos de quatro anos de escolaridade. (AKKARI, 2001). 
Dez anos após a aprovação da Lei de Diretrizes e Bases da Educação Nacional, cujo artigo 87 fixa que ao final da chamada "década da educação", 2007, somente seriam admitidos professores formados em nível superior, verifica-se que $47 \%$ dos professores que atual na Educação Infantil e de primeira e quarta séries do Ensino fundamental não possuem formação em nível superior, o que totaliza cerca de 658 mil professores (BRASIL. MINISTÉRIO DA EDUCAÇÃO. INSTITUTO NACIONAL DE ESTUDOS E PESQUISAS EDUCACIONAIS ANÍSIO TEIXEIRA. Censo escolar, 2006) Com relação aos sistemas de avaliação nacional SAEB e ENEM - observa-se que entre os anos iniciais de aplicação dos exames e os últimos relatórios disponibilizados o desempenho decaiu. Afinal, as ações que vão desde a elaboração e divulgação dos Parâmetros Curriculares Nacionais às pressões que os exames fazem sobre as escolas para que se guiem pelas orientações oficiais não estariam surtindo efeito? Sobre as escolas privadas, o discurso da reforma curricular se faz de maneira mais indireta, isto é, sem o assessoramento e acompanhamento direto por parte dos governos federal, estaduais e municipais. E elas têm obtido um resultado consideravelmente superior em relação às escolas públicas, segundo os critérios do próprio ENEM.

A análise indica assim que, provavelmente em função da polissemia da noção de competências e de suas múltiplas fontes e origens, o que gera interpretações ambíguas no emprego dessa noção por parte das escolas, as ações decorrentes das políticas curriculares e avaliativas pouco interferiram no desempenho dos alunos, não chegando a alterá-lo qualitativamente.

Os resultados apontados sugerem outras possibilidades de interpretação, dentre elas: ou os exames são inadequados, isto é, existe divergência entre aquilo que o exame avalia e o que as escolas priorizam; e/ou as estratégias de convencimento das escolas em direção à adesão ao discurso curricular oficial têm sido inadequadas; e/ou há uma resistência por parte das escolas, consciente ou não, em modificarem suas práticas e se adequarem às prescrições oficiais; e/ou, ainda, as proposições curriculares mostram-se inadequadas quando confrontadas com as práticas existentes e com o que almejam modificar.

Por seu caráter meritocrático, classificatório, mensuratório e quantitativista, esse tipo de prova não oferece, substantivamente, nenhum 
retorno qualitativo às escolas quanto às condições de seu trabalho, quanto ao que gerou este ou aquele processo pedagógico, o que seria preciso rever etc. No entanto, quando os resultados da avaliação mostram uma sucessão de fracassos, a "culpa" recai, primordialmente, sobre os professores e sobre as escolas que fracassaram, apesar de terem obtido os parâmetros e referenciais curriculares "adequados". Ou recai sobre os alunos de "baixa renda" que têm puxado a qualidade do ensino "para baixo", como sinalizam as interpretações oficiais.

A reforma curricular, a reconfiguração da formação de professores e as avaliações nacionais parecem se instituir como mecanismos ideológicos que deslocam a questão do fracasso ou do sucesso escolar da sociedade para o indivíduo - aluno ou professor - e isentam os propositores da reforma educacional de suas responsabilidades. A estruturação da reforma com base na noção de competências favorece esse tipo de análise que centra nos indivíduos a responsabilidade sobre seus processos formativos e desempenhos deles decorrentes.

Os elementos evidenciados na análise permitem confirmar a hipótese de que a centralidade da noção de competências não permite atingir as finalidades anunciadas seja para o redirecionamento das práticas pedagógicas, seja no que se refere aos exames. Por um lado, pelas limitações teóricas e metodológicas próprias dessa noção devidas à multiplicidade de origens e conceituações e, por outro lado, pelos resultados das políticas avaliativas que evidenciam que os resultados de desempenho dos alunos pouco se alteraram desde que tiveram início os procedimentos da reforma. Em síntese, a pesquisa mostra também que as políticas de avaliação pouco se configuram como instrumento de gestão dos sistemas educacionais.

\section{Notas}

1 Importante assinalar que a designação ensino básico, escola básica ou educação básica não é válida para todos os países da América Latina e Caribe. No caso do Brasil, Educação Básica inclui Educação Infantil, Ensino Fundamental e Ensino Médio. (BRASIL, 1996)

2 A execução da avaliação no ano de 1988 ocorreu nos estados do Paraná e do Rio Grande do Sul e não contou com recursos financeiros do Banco Mundial. 
3 O ENEM é composto por uma redação e uma "parte objetiva" com 63 questões com a finalidade de avaliar as cinco competências e as 21 habilidades previstas na "Matriz de Competências". Cada uma das competências é avaliada sob quatro critérios, correspondentes aos conceitos insuficiente, regular, bom e excelente, e as médias obtidas são classificadas segundo as faixas de desempenho "insuficiente a regular", "regular a bom" e "bom a excelente".

4 No momento em que a presente pesquisa é realizada encontram-se disponibilizados pelo INEP os Relatórios Pedagógicos do ENEM até o ano de 2003 e os Relatórios Pedagógicos do SAEB até o ano de 2001, além do Documento SAEB - Série Histórica e Primeiros Resultados de 2005.

\section{Referências}

ABREU, C. B. M.; LANDINI, S. R. Trabalho docente: a dinâmica entre formação, profissionalização e proletarização na constituição da identidade. Quaestio, Revista de Estudos da Educação, Sorocaba, SP, v. 5, n. 1, 2003.

ABREU, C. B. M.; LANDINI, S. R. A formação do professores e profissionalidade docente no quadro da mundialização do capital. Revista Chão da Escola, Curitiba, n. 4, p. 13-18, 10 out. 2005.

ANDRADE, F. A. Reestruturação produtiva, Estado e educação no Brasil de hoje. In: REUNIÃO ANUAL DA ASSOCIAÇÃO NACIONAL DE PÓS-GRADUAÇÃO E PESQUISA EM

EDUCAÇÃO, 24., 2001. Caxambu, MG. Anais... Caxambu, MG, ANPEd, 2001.

APPLE, M. Trabalho docente e textos: economia política das relações de classe e de gênero em educação. Porto Alegre: Artes Médicas, 1995.

AKKARI, A. J. Desigualdades educativas estruturais no Brasil: entre estado, privatização e descentralização. Educação e Sociedade, Campinas, SP, v. 22, n. 74, abr. 2001. Disponível em: <http://www.scielo.br/scielo.php ?pid=S010173302001000100010\&script=sci_arttext\&tlng=pt.. . Acesso em: 23 out. 2007. 
BONAMINO, A. Tempos de avaliação educacional: o SAEB, seus agentes, referências e tendências. Rio de Janeiro: Quartet, 2002.

BRASIL. Conselho Nacional de Educação. Câmara da Educação Básica. Parecer 15/98. Diretrizes Curriculares Nacionais para o Ensino Médio. Brasília, 1998.

BRASIL. Ministério da Educação. Lei 9394/96 de 20 de dezembro de 1996. Lei de Diretrizes e Bases da Educação Nacional. Brasilia, 1996.

BRASIL. Ministério da Educação. Plano Decenal de Educação para todos: 1993-2003. Brasília, 1993.

BRASIL. Ministério da Educação. Instituto Nacional de Estudos e Pesquisas Educacionais Anísio Teixeira. Censo escolar. Brasília, 2006.

BRASIL. Ministério da Educação. Instituto Nacional de Estudos e Pesquisas Educacionais Anísio Teixeira. Censo escolar: sinopse estatística da educação básica 1991-1995. Brasília, 2003.

BRASIL. Ministério da Educação. Instituto Nacional de Estudos e Pesquisas Educacionais Anísio Teixeira. Documento básico do ENEM: 1998. Brasília, 2002.

BRASIL. Ministério da Educação. Instituto Nacional de Estudos e Pesquisas Educacionais Anísio Teixeira. ENEM: concepções e fundamentos. Brasília, 2007. Disponível em: < http://www.inep.gov.br/ enem>. Acesso em: 17 jul. de 2007.

BRASIL. Ministério da Educação. Instituto Nacional de Estudos e Pesquisas Educacionais Anísio Teixeira. ENEM: relatórios pedagógicos: 2001, 2002, 2003. Brasília, 2007. Disponíveis em: < http://www.inep. gov.br/enem>. Acesso em: 23 out. 2007.

BRASIL. Ministério da Educação. Instituto Nacional de Estudos e Pesquisas Educacionais Anísio Teixeira. SAEB 2005: primeiros resultados: médias de desempenho do $\mathrm{SAEB} / 2005 \mathrm{em}$ perspectiva comparada. Brasília, 2007. Disponível em: <http://www.inep.gov.br/ download/saeb/2005/SAEB1995_2005.pdf>. Acesso em: 23 out. de 2007.

BRASIL. Ministério da Educação. Instituto Nacional de Estudos e Pesquisas 
Educacionais Anísio Teixeira. SAEB: relatórios pedagógicos: 1995, 1997, 1999, 2001. Brasilia, 2002. Disponível em: <http://www.inep.gov.br/basica/ saeb/anos_anteriores.htm>. Acesso em: 23 out. 2007.

BRASIL. Ministério da Educação. Secretaria de Educação Média e Tecnológica. ENEM: documento básico. Brasília, 2000.

BRASIL. Ministério da Educação. Secretaria de Educação Média e Tecnológica. Parâmetros curriculares nacionais para o ensino médio. Brasília, 1999.

CEPAL-UNESCO. Educación y conocimiento. Eje de la transformación productiva com equidad. México. 1990. Disponível em: <http://www.lie. upn.mx/docs/Especializacion/Politica/Lec_Equida.pdf>. Acesso em: 23 out. 2007.

DELORS, J. Educação: um tesouro a descobrir. 4. ed. São Paulo: Cortez; Brasilia, DF: MEC/UNESCO, 2000. Relatório para a UNESCO da Comissão Internacional sobre educação para o século XXI.

DIAS, R.; LOPES, A. C. Competências na formação de professores no Brasil: o que (não) há de novo. Educação e Sociedade, Campinas, SP, v. 24, n. 85, p. 1155-1177, dez. 2003.

FERRETI, C. J. Formação profissional e reforma do ensino técnico no Brasil: anos 90. Educação \& Sociedade, Campinas, SP, v. 18, n. 59, p. 225269, ago.1997.

FREITAS, H. C. L. de. Certificação docente e formação do educador: regulação e desprofissionalização. Educação e Sociedade, Campinas, SP, v. 24, n. 85, p. 1095-1124, dez. 2003.

FREITAS, H. C. L. de. Formação de Professores no Brasil: 10 anos de embate entre projetos de formação. Educação e Sociedade, Campinas, São Paulo, v. 23, n. 80, p. 136-167, setembro. 2002.

GIROUX, H. Escola crítica e política cultural. São Paulo: Cortez, 1988.

LOPES, A. C. Competências na organização curricular da reforma do ensino médio. Boletim SENAC. Disponível em: < http:// www.senacnacional.br/informativo/BTS/273/boltec273a.htm. >. Acesso em: 23 out. 2007. 
MACHADO, L. R. S. A institucionalização da lógica das competências no Brasil. Proposições, Campinas, SP, v. 13, n. 1(37), p. 92-110, jan./abr. 2002.

MANFREDI, S. M. Trabalho, qualificação e competência profissional: das dimensões conceituais e políticas. Educação \& Sociedade, Campinas, SP, v. 19, n. 64, set. 1998.

MELLO, G. N. Cidadania e competitividade. 7. ed. São Paulo: Cortez, 1998.

MORAES, M. C. M. Recuo da teoria: dilemas na pesquisa em educação. Revista Portuguesa de Educação, Braga, v. 14. n. 1, p.7-25, 2001.

MOREIRA, A . F.; SILVA, T. T. (Org.). Currículo, cultura e sociedade. 2. ed. revista. São Paulo: Cortez, 1995.

RAMOS, M. A pedagogia das competências: autonomia ou adaptação? São Paulo: Cortez, 2001.

REIS, E. J. F. B. dos, ARAUJO, T. M. de, CARVALHO, F. M. et al.

Docência e exaustão emocional. Educação e Sociedade, Campinas, SP, v. 27, n. 94, p. 229-253, 2006.

SALLES, F. C. A proposta CEPAL-OREALC: progresso técnico, cultura, política e educação. Perspectiva, Florianópolis, n. 18, p. 107-132, ago. 1992. Trabalho e educação numa sociedade em mudança. Santa Catarina.

SAVIANI, D. A nova Lei da educacão: trajetória, limites e perspectivas. 2. ed. rev. Campinas, SP: Autores Associados, 1997.

SHIROMA, E.; MORAES, M. C. M.; EVANGELISTA, O. Política educacional. Rio de Janeiro: DP\&A, 2000.

SILVA, Mônica Ribeiro. Currículo e competências: a formação administrada. São Paulo: Cortez, 2007.

SOUZA, K. R. et al. Trajetória do Sindicato Estadual dos Profissionais da Educação do Rio de Janeiro (SEPE-RJ) na luta pela saúde no trabalho. Ciência e Saúde Coletiva, São Paulo, v. 8, n. 4, p. 1057-1068, 2003. 


\section{Why reform? educational po- licies of the 1990s, the "new teacher education project" and the results of the national evaluations}

\begin{abstract}
:
Brazil is experiencing a context of educational reform since the beginning of the 1990s. This paper proposed situating Brazilian education in the realm of public policies and initially conducts a brief history and contextualization of educational reform of the period. It identifies the first declarations and relates them to education conditions in the country at the time when the reform began. The paper discusses the role and guidelines of international and multilateral agencies in the formulation of local policies. It identifies the creation of interlocutors whose purpose is to promote the viability of and compliance with the goals established in the partnerships, and to give responses to the partner agents. The work demonstrates that one of the principal targets of the reform was curriculum change, used as a strategy to approximate school education to the demands made by the transformations occurred in the economy in general, and in the world of labor in particular. It reveals the consolidation of a new project for education highlighted by teacher education. Finally, it analyzes the results of this reform process, using as a reference the performance of the students gauged by means of national evaluation systems.
\end{abstract}

\section{Reformas para qué? Las po- líticas Educacionales de los años 90, el "nuevo projeto de formación" y los resultados de las evaluaciones nacionales}

\section{Resumen:}

El Brasil vive un contexto de reforma educacional desde el inicio de los años 90. El presente trabajo se propone situar la educación brasilera en el ámbito de las políticas públicas realizando inicialmente un breve histórico y contextualización de la reforma educacional en ese período. Identifica sus primeros enunciados relacionándolos a las condiciones de educación vigentes en el momento en que la reforma tuvo inicio en el país. Discute el papel que vienen ocupando las agencias internacionales y las orientaciones de los organismos multilaterales en la formulación de las políticas locales. En ese contexto, señala la creación de interlocutores cuya finalidad es de promover y viabilizar el cumplimiento de las metas y compromisos establecidas, como así también dar respuestas a los agentes. El trabajo demuestra que uno de los principales pontos de la reforma fue el cambio curricular, utilizado como estrategia para aproximar la educación escolar a las demandas colocadas por las transformaciones ocurridas en la economía en general y en el mundo del trabajo, en particular. Evidencia la consolidación de un nuevo proyecto de formación, en especial la formación de profesores. Finalmente analiza, los resultados del proceso de la reforma to- 
Key words: Educational ReformBrazil. Educational Evaluation-Brazil. Public Policy-Brazil. mando como referencia el desempeño atribuido a los estudiantes por medio de los sistemas de evaluación.

Palabras-clave: Reforma de Enseñanza-Brasil. Evaluación educacional-Brasil. Políticas públicas-Brasil.

Mônica Ribeiro da Silva

Rua General Carneiro, 460, CEP: 80060-140 - Curitiba, PR E-mail:monicars@ufpr.br

\section{Claúdia Barcelos de Moura Abreu}

Rua General Carneiro, 460,

CEP: 80060-140 - Curitiba, PR

E-mail: claudiabarcelos@ufpr.br

Recebido em: 10/11/2007

Aprovado em: 15/2/2008 